\section{Mental illness moves into the genetics lab}

Santa Barbara. California

THE National Institute of Mental Health (NIMH) has travelled further down the road from the therapist's couch to the sequencing gel, with a call for grant applications in molecular neurobiology. Underscoring its commitment to molecular approaches to mental illness, it sponsored a three-day conference on molecular neurobiology here last week, designed as a 'mixer' to encourage the flow of ideas between NIMH researchers and molecular biologists.

The NIMH's commitment to mental health has taken many forms over the four decades since its inception, with support for basic research at times overshadowed by service functions. NIMH played a role in the management of community outpatient programmes during the heyday of belief in the 'social cure' in the 1960s.

The current trend towards increased support for basic research has its roots in the formation, in 1981, of the institute's Neurosciences Research Branch. The subsequent recommendation, by panels of leading neuroscientists, of vigorous support for molecular biology, arose out of the recognition that mental illness is likely to have genetic components.

"We're optimistic about the payoff from molecular biology", said Stephen Koslow, head of the Neurosciences Research Branch. Koslow hopes to persuade researchers working on genetic and molecular mechanisms of nerve cell function and development to consider how their systems may illuminate underlying causes and potential treatments of mental illness. There has been much progress in recent years, for example in the cloning of the genes for neurotransmitter and hormone receptor systems, as well as ion channels, and enzymes involved in neurotransmitter synthesis. Within the next decade, NIMH hopes research will reveal connections between genetic errors and various forms of mental illness.

Eric Kandel, of Columbia University, keynote speaker at last week's conference and long-time recipient of NIMH funding, does the sort of work the institute wants to support, said Steven Zalcman, head of the neurobiology programme. Kandel has taken his studies of learning and memory in the sea slug, Aplysia, from the level of neural circuitry to analysis of the molecular mechanism of memory storage. In addition to increasing its portfolio of grants to individual molecular biologists, NIMH hopes that its January 1988 Decade of the Brain report will "light a fire under Congress". said Zalcman.

\title{
Shake-up proposed for all four of the UK research councils
}

London

THE long-running debate about the division of responsibilities between Britain's four scientific research councils has resurfaced, with three of the councils insisting that the time is ripe for change. Only the largest of the four, the Science and Engineering Research Council (SERC), wants to retain the status quo under the proposals being put forward, it would stand to lose its role in the biological sciences.

The various schemes have been suggested during evidence to a House of Lords select committee that is examining Britain's food and agricultural interests. The most radical proposal has been put forward by the Natural Environment Research Council (NERC), which says that the "previously fairly clear" divisions of responsibility between the different councils has become blurred and confused, "with the likelihood of increasing overlap and duplication". NERC proposes to amalgamate with the Agricultural and Food Research Council (AFRC) to create a Natural Resources Research Council. NERC cites several areas of common interest, such as forestry and land use, to support its case. The new council would retain the councils' biological interests in order to keep "the vital links between the biological and physical sciences". AFRC's solution is to establish a single nonmedical biological research council.

The Medical Research Council (MRC) firmly holds that the biological science research administered by the SERC would be better farmed out to the three 'mission-led' councils. It cites SERC's programmes in plant and amimal biochemistry and physiology as well as "many components of its biotechnology programme" as areas which make it "inherently difficult to coordinate initiatives effectively". MRC says that while it successfully developed mechanisms with the AFRC to coordinate activities, attempts to do the same with SERC had failed. MRC is opposed to the establishment of a single biological research council.

SERC makes a spirited defence of the present system. It points out that its annual expenditure on non-clinical biology is $£ 23$ million. It supports 1,700 research students in biology, of whom 600 are on industrially sponsored schemes.

Because of its other interests it is best placed to encourage close collaboration in fundamental and strategic areas between the life scientists and the physical and chemical scientists and mathematicians supported through its science board. Its interests in engineering research provide a valuable means of exploiting biology. Current systems for cooperation and coordination between the research councils are sufficient to avoid substantial overlap and duplication, SERC maintains. It will be for the Advisory Board for the Research Councils to try to make some sort of sense of the conflicting schemes.

Simon Hadlington

\section{Switch to PWR could produce skills shortage}

\section{London}

BRITISH industry and government were warned last week that the renaissance of the nuclear power programme, which until last year had lain dormant for almost a decade, could expose a vacuum in skilled manpower, resulting in increased reliance on imports of power station components and fuel. In an assessment of the industrial impact of the decision to construct a pressurized water reactor (PWR) at Sizewell, in Suffolk, the government's Advisory Council on Science and Technology (ACOST) says that although the decision to embark on a PWR-based programme was not likely to result in a severe immediate shortage of available manpower in research, development or design, if all the power stations were built too close together in time, or if there was a significant, simultaneous coal-fired power station building programme, "there could be difficulties due to an inadequate supply of sufficiently well trained and experienced project managers and site personnel",

Since permission was granted for the construction of a PWR at Sizewell early last year, the Central Electricity Generating Board (CEGB) has made clear its intention to build a family of identical reactors. ACOST supports CEGB's position that all efforts should now be directed towards the construction of the PWR and that no new advanced gas-cooled reactors should be built.

On the question of Britain's fast reactor research programme, currently the subject of intense debate and speculation, given that the electricity supply industry is soon to be privatized, ACOST notes "with approval" that funding for the project (which totalled $£ 128$ million last year) is moving increasingly away from the government to the CEGB and recommends "that this process should be encouraged".

Simon Hadlington

The Industrial Impact of Sizewell 'B'. ACOST (HMSO, London, £4.90). 